\title{
Molecular Characteristics of Fluoroquinolone- Resistant Escherichia Coli Isolated From Suckling Piglets With Colibacillosis
}

Kwang Won Seo

Chungbuk National University

Kyung-Hyo Do

Chungbuk National University

Wan-Kyu Lee ( $\nabla$ wklee@cbu.ac.kr)

Chungbuk National University

\section{Research Article}

Keywords: Escherichia coli, colibacillosis, antimicrobial resistance, fluoroquinolone, plasmid-mediated quinolone resistance

Posted Date: June 28th, 2021

DOl: https://doi.org/10.21203/rs.3.rs-648457/v1

License: (c) (i) This work is licensed under a Creative Commons Attribution 4.0 International License. Read Full License 


\section{Abstract}

Objectives: Colibacillosis is a frequent enteric disease in the pig industry that causes significant economic losses. The objective of this study was to investigate the phenotypic and genotypic characteristics of fluoroquinolone (FQ)-resistant $E$. coli isolates from suckling piglets with colibacillosis.

Results: A total of 43 FQ-resistant E. coli isolates were tested in this study and all isolates showed multidrug resistance (MDR) and mutations in quinolone resistance determining regions ( $g y r A$ or parC). In particular, $\mathrm{FQ}$-resistant $E$. coli isolates with a high $\mathrm{FQs} \mathrm{minimum} \mathrm{inhibitory} \mathrm{concentration} \mathrm{range}(\geq 64$ $\mathrm{mg} / \mathrm{L}$ for ciprofloxacin, $\geq 128 \mathrm{mg} / \mathrm{L}$ for enrofloxacin, and $\geq 256 \mathrm{mg} / \mathrm{L}$ for norfloxacin) were shown to carry double mutations in gyrA in combination with double mutations in parC. A total of 12 (27.9\%) isolates were positive for the plasmid-mediated quinolone resistance (PMQR) genes, and aac(6')-lb-cr (7 isolates), qnrS (3 isolates), and qepA (2 isolates) were also positive. We identified the following in PMQR-positive $E$. coli isolates: $\beta$-lactamases-encoding blaCMY-2 (10 isolates, 83.3\%), blaTEM-1 (7 isolates, $58.3 \%)$, blaOXA-1 (7 isolates, $58.3 \%)$, blaSHV-1 (3 isolates, $16.7 \%)$, and blaAAC-2 (1 isolate, $8.3 \%)$; the tetracycline resistance genes $\operatorname{tet} D(12$ isolates, $100.0 \%)$, tet $E$ ( 12 isolates, $100.0 \%)$, $\operatorname{tet} A(11$ isolates, $91.7 \%)$, and tet $B$ (1 isolate, $8.3 \%$ ); the aminoglycoside modifying enzyme gene aac(3)-II (2 isolates, $16.7 \%)$; the sulfonamide resistance genes sul1 (9 isolates, 75.0\%) and sul2 (10 isolates, $83.3 \%$ ); and the chloramphenicol resistance genes (10 isolates, $83.3 \%$ ). The most prevalent fimbrial antigen, combinations of toxin genes, and non-fimbrial adhesins genes were F4 (7 isolates, 58.3\%), LT:STb:EAST1 (5 isolates, $41.7 \%$ ), and paa (3 isolates, $25.0 \%$ ), respectively. Although all PMQR-positive E. coli carried class I integrons, only 4 isolates carried the gene cassette arrangement. The most common plasmid replicon was FIB (9 isolates, $75.0 \%$ ), followed by FIC, HI1, and N (7 isolates, 58.3\%), respectively.

Conclusions: Because FQ resistant genetic determinants that can be transferred to pathogenic bacteria in humans or pigs, critical need for comprehensive surveillance of antimicrobial resistance on pig farms.

\section{Background}

Colibacillosis caused by Escherichia coli (E. coli) in pigs is the most frequent enteric disease and an important cause of death in suckling piglets. This disease may result in significant economic losses in the pig industry because of mortality, decreased weight gain, and costs for treatments, vaccinations and feed supplements [1]. The use of antimicrobial drugs such as $\beta$-lactams, aminoglycosides, and fluoroquinolones (FQs) has remained the primary option for controlling colibacillosis.

FQs have been used effectively antimicrobials worldwide for the treatment of various infections caused by $E$. coli or other gram-negative bacteria. The World Health Organization (WHO) has classified FQs as "critically important antimicrobials" because of their clinical importance in both human and animal medicine [2]. Because the importance of FQs in humans and animals is increasing, FQ-resistant bacteria are a major concern in the treatment of infectious diseases. Notably, since enrofloxacin has been licensed for veterinary use since 1987 in Korea [3], and FQ-resistant E. coli have developed over this period. 
Multiple mechanisms are involved in resistance to $\mathrm{FQ}$ in Enterobacteriaceae. The major mechanisms of resistance to FQ involve mutations of chromosomal genes encoding DNA gyrase and/or topoisomerase IV $[4,5]$. In addition, three different plasmid-mediated quinolone resistance (PMQR) determinants have been described: qnr-mediated inhibition of quinolone binding to DNA [6, 7], qepA encoded efflux pump [8], and the $\operatorname{aac}\left(6^{\prime}\right)-I b-c r$ mediated FQ acetylation $[9,10]$. The PMQR genes confer only low-level resistance to FQ; however, they can be spread horizontally among enterobacteria and facilitate the selection of resistant mutants following exposure to $\mathrm{FQ}$ [11]. Although studies from several countries have documented the prevalence and characteristics of FQ-resistance in healthy pigs [12-14], there is still limited information regarding the molecular characteristics of FQ-resistant and PMQR-positive E. coli isolated from suckling piglets with diarrhea. Therefore, the purpose of this study was to investigate the phenotypic and genotypic characteristics of FQ-resistant $E$. coli isolates from suckling piglets with colibacillosis.

\section{Materials And Methods}

\section{Bacterial isolates}

E. coli isolates collected from each colibacillosis clinical case in suckling piglets from 2007-2018 were tested. The farms consisted of 42 different pig herds (50 to 100 sows per each herd). The aseptically collected intestinal contents and feces were inoculated on MacConkey agar(BD Biosciences, Sparks, MD) containing $4 \mathrm{mg} / \mathrm{mL}$ of ciprofloxacin (CIP; Sigma-Aldrich, St.Louis, MO). Subsequently, suspected $E$. coli colonies were identified by VITEK II system (bioMéreiux, France). Thus, a total of 43 CIP-resistant $E$. coli were tested in this study.

\section{Antimicrobial susceptibility testing}

The disk diffusion method was performed according to the Clinical and Laboratory Standards Institute (CLSI) guidelines [15]. The 19 antimicrobial disks (BD Biosciences) used in this study were amikacin (30 $\mu \mathrm{g})$, amoxicillin-clavulanate $(20 / 10 \mathrm{mg})$, ampicillin (10 mg), aztreonam $(30 \mu \mathrm{g})$, cefazolin $(30 \mu \mathrm{g})$, cephalothin $(30 \mu \mathrm{g})$, cefoxitin $(30 \mu \mathrm{g})$, cefepime $(30 \mu \mathrm{g})$, chloramphenicol $(30 \mathrm{mg})$, colistin $(10 \mathrm{mg})$, doxycycline $(30 \mu \mathrm{g})$, gentamicin $(10 \mathrm{mg})$, kanamycin $(30 \mathrm{mg})$, nalidixic acid (30 mg), neomycin (30 mg), penicillin $(10 \mathrm{U})$, streptomycin $(10 \mathrm{mg})$, tetracycline $(30 \mathrm{mg})$, and trimethoprim-sulfamethoxazole $(1.25 / 23.75 \mathrm{mg})$. The minimum inhibitory concentration (MIC) for CIP, enrofloxacin (ENR), and norfloxacin (NOR) was determined by standard agar dilution methods using the Mueller-Hinton agar (BD Biosciences) method according to the guidelines of the CLSI [15]. The breakpoints of CIP, NOR, and ENR were also determined according to the guidelines of the CLSI [15]. E. coli ATCC 25922 was included as a quality control. Multidrug-resistance (MDR) was defined as acquired resistance to at least one agent in three or more antimicrobial classes [16].

\section{0-Serogroup typing}


O-serogroup typing was performed using rabbit antisera purchased from SSI (Serum Staten Institute, Denmark) with the slide agglutination technique of the Animal and Plant Quarantine Agency (Gimcheon, Korea). A standard strain was obtained from Dr. J.M. Fairbrother (OIE E. coli Reference Laboratory, Quebec, Canada).

\section{Identification of mutations in quinolone-resistance-determining regions and detection of plasmid- mediated quinolone-resistance genes}

PCR was carried out to amplify quinolone resistance determining regions (QRDRs) of the target genes (gyrA, and parC) to identify mutations in $43 \mathrm{FQ}$-resistant E. coli isolates using primers and conditions described previously $[17,18]$. The PCR products were purified using GFX PCR DNA and the gel band purification kit (Amersham Bioscience, Freiburg, Germany), and sequenced by an automatic sequencer (Cosmogenetech, Seoul, Korea). The sequences were matched with those in the GenBank nucleotide database using the Basic Local Alignment Search Tool (BLAST) program available through the National Center for Biotechnology Information website (http://www.ncbi.nlm.nih.gov/BLAST). PMQR genes (qnrA, $q n r B, q n r C, q n r D, q n r S$, aac( $\left.6^{\prime}\right)-I b-c r$, and $\left.q e p A\right)$ were detected by PCR amplification and sequencing analysis, as described in Table 1.

\section{Molecular analysis}

For detection of antimicrobial resistance genes and virulence genes, PCR was performed using DNA extracted from PMQR-positive E. coli isolates. Primers used in the study are listed in Table 1. All PMQRpositive $E$. coli isolates were tested for resistance genes related to aminoglycosides (aac (3)-II, and ant(2")-I), $\beta$-lactam antimicrobials (bla ${ }_{C T X-M}$ families, bla ${ }_{T E M}, b_{S H V}, b / a_{O X A}$, and pAmpC), chloramphenicols ( $\mathrm{cm} / A$ and catA1), sulfonamides (sul1 and sul2), and tetracyclines (tetA, tetB, tetC, tet $D$, tetE and tetG). The virulence factor genes associated with the toxins (LT, STa, STb, Stx2e, and EAST-1), fimbriae (F4, F5, F6, F18, and F41), and non-fimbrial adhesins (AIDA-1, paa, eae) were also confirmed by PCR as previously described [32].

\section{Plasmid replicon typing and detection of integrons and gene cassettes}

For plasmid replicon typing and detection of integrons and gene cassettes, PCR was performed using DNA extracted from PMQR-positive E. coli isolates. The primers used in this study targeted 18 different replicons [33] and class 1 and 2 integrons (Table 1.). Gene cassettes were tested for integron-positive isolates. The PCR products of the gene cassettes were sequenced as described above.

\section{Transconjugation}

To determine the transferability of PMQR and other genes, conjugation assays were performed using the broth mating method, with E. coli J53 used as the recipient as previously described [34]. Transconjugants were selected on MacConkey agar (BD Biosciences) plates containing sodium azide ( $100 \mu \mathrm{g} / \mathrm{ml}$; Sigma- 
Aldrich) and ampicillin or tetracycline (100 $\mathrm{gg} / \mathrm{ml}$; Sigma-Aldrich). Transferability was confirmed by antimicrobial susceptibility tests and PCR for molecular analysis as described above.

\section{Results}

\section{Antimicrobial resistance}

MDR patterns of FQ-resistant E. coli isolates from colibacillosis are shown in Table 2. Among the 43 FQresistant E. coli, all isolates showed MDR against 6 to 11 classes of antimicrobial agents. The rates of resistance to the various antimicrobial classes were as follows: aminoglycosides (43/43, $100.0 \%)$, penicillins $(43 / 43,100.0 \%)$, quinolones $(43 / 43,100.0 \%)$, tetracyclines $(42 / 43,97.7 \%)$, phenicols $(39 / 43$, $90.7 \%), \beta$-lactam/ $\beta$-lactamase inhibitor combinations (32/43, 74.4\%), folate pathway inhibitors (32/43, $74.4 \%)$, cephems $(31 / 43,72.1 \%)$, monobactams $(7 / 43,16.3 \%)$, and polypeptides $(6 / 43,14.0 \%)$. The rate of resistance to 9 antimicrobial classes was the highest at 39.5\%, and one (2.3\%) FQ-resistant $E$. coli isolate showed resistance to 11 classes.

\section{Characteristics of FQ-resistant $E$. coli}

The molecular characteristics of 43 FQ-resistant E. coli isolates are shown in Table 3. Among the isolates, 36 isolates were classified into 170 -serogroups, and 6 isolates were ungrouped. The most common serogroup was 0149 (12 isolates, 27.9\%). The gyrA amino acid substitutions were S83L (43 isolates), D87N (22 isolates), D87G (5 isolates), and D87E (2 isolates), and the parC mutations were S80I (23 isolates), S80R (9 isolates), E84A (5 isolates), S80K ( 3 isolates), S80N (1 isolates), S80W (1 isolates), E84G (1 isolates), A56C ( 1 isolates), and S57Q (1 isolates). The MIC ranges for CIP, ENR, and NOR were 4-256 mg/mL, 8-512 mg/ml, and 8-512 mg/mL, respectively, and isolates with double mutations in gyrA were relatively higher than those of other isolates with single mutations in gyrA. In particular, FQresistant $E$. coli isolates with a high level of MICs range ( $\geq 64 \mathrm{mg} / \mathrm{L}$ for CIP, $\geq 128 \mathrm{mg} / \mathrm{L}$ for ENR, and $\geq 256 \mathrm{mg} / \mathrm{L}$ for NOR) were shown to carry double mutations in $g y r A$ in combination with double mutations in parC. PMQR genes were detected in $12(27.9 \%)$ of the 43 FQ-resistant $E$. coli isolates. The $\operatorname{aac}\left(6^{\prime}\right)-I b-c r$, qnrS, and qepA genes were identified in seven, three, and two FQ-resistant $E$. coli isolates, respectively. Among $12 \mathrm{PMQR}$-positive $E$. coli isolates, one isolate that showed the highest MICs for CIP (256 mg/mL), ENR (512 mg/mL), and NOR (512 mg/mL), also carried the PMQR gene $\operatorname{aac}\left(6^{\prime}\right)-l / b-c r$.

\section{Characterization of PMQR-positive $E$. coli}

The prevalence of antimicrobial resistance genes is shown in Table 4. All PMQR-positive E. coli isolates carried the following $\beta$-lactamase encoding genes: $b / a_{C M Y-2}$ (10 isolates, $\left.83.3 \%\right), b / a_{T E M-1}$ (7 isolates, $58.3 \%), b_{\text {OXA-1 }}(7$ isolates, $58.3 \%)$, bla SHV-1 ( 3 isolates, $16.7 \%$ ), and $b / a_{A A C-2}(1$ isolate, $8.3 \%$ ). Tetracycline-resistance genes were detected in all PMQR-positive $E$. coli isolates as follows: $\operatorname{tet} D(12$ isolates, $100.0 \%)$, tetE (12 isolates, $100.0 \%$ ), tet $A$ (11 isolates, $91.7 \%$ ), and tet $B$ ( 1 isolate, $8.3 \%$ ). Two types of aminoglycoside-modifying enzyme genes were examined, but aac(3)-I/ was found only in 2 (16.7\%) PMQR-positive E. coli isolates. The sul1 and sul2 sulfonamide-resistance genes were detected in 
9 isolates (75.0\%) and 10 isolates (83.3\%), respectively. The $\mathrm{cm} / \mathrm{A}$ chloramphenicol-resistance gene was found in 10 isolates (83.3\%). Distributions of the virotypes are shown in Table 4. Seven (58.3\%) and two $(16.7 \%)$ of the isolates contained fimbrial antigen F4 and F41, respectively. The most prevalent combinations of toxin genes were LT:STb:EAST1 (5 isolates, $41.7 \%$ ), followed by EAST1 (3 isolates, 25.0\%), LT:STa:STb (1 isolates, 8.3\%), STa:STb:EAST1 (1 isolates, 8.3\%), STa:STb (1 isolates, 8.3\%), Sta (1 isolates, 8.3\%). The paa and AIDA non-fimbrial adhesins genes were detected in 3 isolates $(25.0 \%)$ and 2 isolates (16.7\%), respectively. Among $12 \mathrm{PMQR}$-positive FQ-resistant $E$. coli isolates, all isolates were found to have class 1 integrons. Class 1 integrons contained four types of gene cassette arrangements, aadA1-dfrA1 (2 isolates), aadA1-aadA2- aadB (1 isolate), and aadA1-aadA2- aadB-cm/A6 (1 isolate). Eight isolates did not carry any of the gene cassettes. A total of 10 plasmid replicon types were identified in all 12 PMQR-positive $E$. coli isolates. The most common plasmid replicon was FIB (9 isolates, $75.0 \%$ ), followed by FIC, HI1, and N (7 isolates, 58.3\%), respectively. Transferability was only identified in 7 isolates among $12 \mathrm{PMQR}$-positive $\mathrm{FQ}-$ resistant $E$. coli isolates.

\section{Discussion}

Suckling piglets are vulnerable to colibacillosis for many reasons such as changes in environmental conditions, a decline in maternal antibody titers, and various stresses. Antimicrobials are used in intensive pig production systems to control infectious diseases. In particular, FQs are highly effective antimicrobial class with many advantages including high oral absorption, large volume of distribution, and broad-spectrum antimicrobial activity [35]. However, increasing use of these agents has led to rising rates of resistance to FQs in E. coli worldwide [36]; thus, the probability of treatment failure may be increased [37]. In this study, all FQ-resistant E. coli isolates showed were MDR (resistance to more than six antimicrobial agents) with high levels of resistance to several antimicrobials: aminoglycosides (100.0\%), penicillins (100.0\%), tetracyclines (97.7\%), and phenicols $(90.7 \%)$. In particular, five isolates showed resistance to more than 10 classes. These results were consistent with previous studies showing co-association of resistance to other classes of antimicrobials and high MDR rates among FQ-resistant $E$. coli $[38,39]$. This occurs because PMQR genes and other antimicrobial-resistance genes are linked together on the plasmid [38].

The O-serogroup is considered one of the major virulence factors of $E$. coli and variety of O-serogroups has been associated with diarrhea [40-42]. In the present study, 17 0-serogroups were detected and 0149 was most common. The 0149 serogroup has been determined to be the dominant serogroup in cases of diarrhea in many countries including China and Canada $[43,44]$. In addition, in this study, all isolates (100\%) had gyrA mutations, and 29 isolates (67.4\%) were double amino acid substitutions (S83L plus substitution in aspartic acid 87). These results were consistent with previous studies showing that DNA gyrase is the primary target of $\mathrm{FQ}$ in gram-negative bacteria, and gyrA mutations are dominant mutations in E. coli [45]. Moreover, 37 (86.0\%) FQ-resistant E. coli isolates had mutations at codon 80 in parC in the QRDRs, and the most common type of amino-acid substitution was S80I in parC. Previous studies reported that the substitution S80I was most frequently observed among substitutions in the QRDR of parC $[46,47]$. These results are consistent with those observed in $E$. coli isolates from humans $[48,49]$. 
Also, the MICs ranges of isolates with double mutations in gyrA were relatively higher than those of other isolates with single mutations in gyrA. Notably, FQ-resistant $E$. coli isolates carrying double mutations in gyrA in combination with double mutations in parC were identified at high levels of MICs $(\geq 64 \mathrm{mg} / \mathrm{L}$ for $\mathrm{CIP}, \geq 128 \mathrm{mg} / \mathrm{L}$ for ENR, and $\geq 256 \mathrm{mg} / \mathrm{L}$ for NOR). These results are consistent with those of recent studies showing that the total number of point mutations in QRDR was positively correlated with the increased MIC.

In this study, 12 FQ-resistant $E$. coli isolates carried three types of PMQR genes, aac(6')-Ib-cr (7 isolates), qnrS (3 isolates), and qepA ( 2 isolates). These PMQR variants have been previously detected in $E$. coli from livestock, including in healthy animals and retail meats in the Czech Republic [50], China [51], and the United States [52], as well as from swine in Korea [13]. Also, to acquire FQ resistance, bacteria usually require at least double mutations in QRDRs [53]. However, in this study, two isolates (4 mg/L for CIP, 8 $\mathrm{mg} / \mathrm{L}$ for ENR, and $8 \mathrm{mg} / \mathrm{L}$ for NOR) had only a single mutation in gyrA and harbored qnrSin its plasmid. This result showed that PMQR genes play a role in FQ resistance [54].

The rise of antimicrobial resistance is thought to be closely associated with the widespread transfer of resistance genes between bacterial species. In this study, all 12 PMQR-positive $E$. coli isolates carried a variety of antimicrobial resistance genes such as blaCMY, blaTEM, blaOXA, blaSHV, blaAAC, tetA, tetB, tetD, tetE, aac(3)-II, sul1, sul2, and $\mathrm{cm} / A$ and harbored mobile elements such as integrons and gene cassettes at the same time. The bla genes hydrolyze the characteristic $\beta$-lactam ring and confer resistance to most $\beta$-lactam antimicrobials, including cephalosporins [55]. Previous studies reported that the PMQR genes in bla positive-E. coli were detected at high levels [56]. The presence of the PMQR genes may be significantly associated with the $\beta$-lactamase gene, perhaps due to common carriage on a plasmid in Enterobacteriaceae [57]. Also, all 12 PMQR-positive E. coli isolates harbored class 1 integrons and four isolates also contained gene cassettes aadA or $d f r A$ or both genes. These genes are frequently detected in class 1 integrons isolated from animals and humans in Korea [58]. Therefore, integrons in $\mathrm{PMQR}$-positive $E$. coli isolates from suckling piglets may have acquired the genetic determinants of drug resistance, which could become a concern.

Plasmids are small DNA molecules that are distinct from chromosomes and can provide beneficial effects to bacteria such as antibiotic resistance through horizontal gene transfer [33]. In this study, 10 plasmid replicon types were identified in all $12 \mathrm{PMQR}$-positive $E$. coli isolates. The most common plasmid replicon was IncF plasmids including FIB, and FIC. IncF plasmids were associated with the important role in the spread of virulence and resistance to important classes of antimicrobials including quinolones, $\beta$ lactams, TEs, sulfonamides, chloramphenicol, and aminoglycosides among Enterobacteriaceae [59].

The detection of $E$. coli virulence factors is important for diagnosing and establishing preventative measures for colibacillosis [60]. In this study, toxin genes LT, STb, and Sta were detected in nine $(75.0 \%)$, nine (75.0\%), and one (8.3\%) PMQR-positive E. coli isolates, respectively. These LT, STa, and STb genes damage the vessel and cause edema and a high mortality in pigs [61]. Also, the most prevalent fimbriae antigen was F4 (7 isolates, 58.3\%). F4 fimbriae have been frequently detected in piglets in several 
countries such as Japan, Europe, and the United States [62-64]. Previous studies reported that paa is known to have a high association with $\mathrm{F} 4[62,65]$. In this study, 6 (50.0\%) PMQR-positive $E$. coli isolates were identified as having the paa gene and coexisting with the F4 gene. Although the specific role of the paa gene in the development of pathogenic $E$. coli has not yet been clearly defined, various virotypes may also appear as a result of horizontal gene transferability of the paa gene [66].

\section{Conclusions}

This study investigated the molecular characteristics of FQ-resistant $E$. coli isolated from suckling piglets with colibacillosis. All FQ-resistant E. coli isolates showed an MDR phenotype, and the most prevalent of the mutations were double point mutations in gyrA and a single mutation in parC. Also, FQ-resistant $E$. coli isolates with PMQR genes carried various antimicrobial genes and harbored mobile elements and plasmid replicons. Antimicrobial resistance may become a serious problem because many drugs are probably ineffective for the treatment of colibacillosis and resistance elements can be horizontally transferred on pig farms. Also, this represents a public health hazard because FQ-resistant E. colican serve as a reservoir of $F Q$ resistant genetic determinants that can be transferred to pathogenic bacteria in humans or pigs. These data support the critical need for comprehensive surveillance of antimicrobial resistance on pig farms.

\section{Abbreviations}

E. coli: Escherichia coli; FQ: Fluoroquinolone; CIP: Ciprofloxacin; PMQR: Plasmid-mediated quinolone resistance; MIC: Minimum inhibitory concentration; ENR: Enrofloxacin; NOR: Norfloxacin; MDR: Multidrugresistance; QRDRs: Quinolone resistance determining regions

\section{Declarations}

\section{Ethics approval and consent to participate}

Not applicable.

\section{Consent for publication}

Not applicable.

\section{Availability of data and materials}

All data generated or analysed during this study are included in this published article

\section{Competing interests}

The authors declare that they have no conflict of interest. 


\section{Funding}

This work was supported by "Korea Institute of Planning and Evaluation for Technology in Food, Agriculture, Forestry and Fisheries (IPET) through Agriculture, Food and Rural Affairs Convergence Technologies Program for Educating Creative Global Leader, funded by Ministry of Agriculture, Food and Rural Affairs (MAFRA) (grant number: 320005-4)".

\section{Authors' contributions}

KWS and WKL, designed the study. KWS and KHD conducted the experiments. KWS and KHD performed the data arrangement. KWS wrote and edited the manuscript. KHD carried out the statistical analysis. KWS, KHD and WKL assumed overall responsibility for the accuracy and integrity of the manuscript. All authors read and approved the final manuscript.

\section{Acknowledgements}

Not applicable.

\section{Author details}

Laboratory of Veterinary Bacteriology and Infectious Diseases, College of Veterinary Medicine, Chungbuk National University, Cheongju 28644, Korea

\section{References}

1. Fairbrother JM, Gyles CL. Colibacillosis. In: Zimmerman JJ, Karriker LA, Ramirez A, Schwartz KJ, Stevenson GW, editors. Disease of Swine. 2012;10th ed:p. 723-47.

2. WHO. Critically Important Antimicrobials for Human Medicine - 5th Rev. World Health Organization, Geneva. 2017.

3. Korea Animal Health Products Association (KAHPA). Animal health products handbook. KAHPA, Sungnam, Korea. 2001.

4. Yoshida $\mathrm{H}$, Bogaki $\mathrm{M}$, Nakamura $\mathrm{M}$, Nakamura $\mathrm{S}$. Quinolone resistance determining region in the DNA gyrase gyrA gene of Escherichia coli. Antimicrob Agents Chemother 1990;34:1271-2.

5. Heisig P. Genetic evidence for a role of parC mutations in development of high-level fluoroquinolone resistance in Escherichia coli. Antimicrob Agents Chemother 1996;40:879-85.

6. Tran JH, Jacoby GA. Mechanism of plasmid mediated quinolone resistance. PNAS 2002;99:5638-42.

7. Poirel L, Rodriguez-Martinez JM, Mammeri H, Liard A, Nordmann P. Origin of plasmid-mediated quinolone resistance determinant QnrA. Antimicrob Agents Chemother 2005;49:3523-5. 
8. Yamane K, Wachino JI, Suzuki S, Kimura K, Shibata N, Kato H, et al. New plasmid-mediated fluoroquinolone efflux pump, QepA, found in an Escherichia coli clinical isolate. Antimicrob Agents Chemother 2007;51:3354-60.

9. Park CH, Robicsek A, Jacoby GA, Sahm D, Hooper DC. Prevalence in the United States of aac (6')-Ibcrencoding a ciprofloxacin-modifying enzyme. Antimicrob Agents Chemother 2006;50:3953-5.

10. Robicsek A, Strahilevitz J, Jacoby GA, Macielag M, Abbanat D, Park $\mathrm{CH}$, et al. Fluoroquinolonemodifying enzyme: a new adaptation of a common aminoglycoside acetyltransferase. Nat Med 2006a;12:83-8.

11. Robicsek A, Jacoby GA. Hooper DC. The worldwide emergence of plasmid-mediated quinolone resistance. Lancet Infect Dis 2006b;6:629-40.

12. Kuo H, Chou C, Tu C, Gong S, Han C, Liao J, et al. Characterization of plasmid-mediated quinolone resistance by the qnrS gene in Escherichia coli isolated from healthy chickens and pigs. Veterinarni Medicina 2009;54:473-82.

13. Hu YS, Shin S, Park YH, Park KT. Prevalence and Mechanism of Fluoroquinolone Resistance in Escherichia coli Isolated from Swine Feces in Korea. J Food Prot 2017;80:1145-51.

14. Cheng P, Yang Y, Li F, Li X, Liu H, Fazilani SA, et al. The prevalence and mechanism of fluoroquinolone resistance in Escherichia coli isolated from swine farms in China. BMC Vet Res 2020;16:258.

15. CLSI. Performance Standards for Antimicrobial Disk and Dilution Susceptibility Tests for Bacteria Isolated from Animals (VET01-S3). 3rd ed. Clinical and Laboratory Standards Institute, Wayne, PA. 2015.

16. Magiorakos AP, Srinivasan A, Carey RB, Carmeli Y, Falagas ME, Giske CG, et al. Multidrug-resistant, extensively drug-resistant and pandrug-resistant bacteria: an international expert proposal for interim standard definitions for acquired resistance. Clin Microbiol Infect 2012;18:268-81.

17. Dutta S, Kawamura Y, Ezaki T, Nair GB, lida K, Yoshida S. Alteration in the GyrA subunit of DNA gyrase and the ParC subunit of topoisomerase IV in quinolone-resistant Shigella dysenteriae serotype 1 clinical isolates from Kolkata, India. Antimicrob Agents Chemother 2005;49:1660-1.

18. Bai H, Du JF, Hu M, Qi J, Cai YN, Niu WW, et al. Analysis of mechanisms of resistance and tolerance of Escherichia coli to enrofloxacin. Ann Microbiol 2012;62:293-8.

19. Wang M, Tran JH, Jacoby GA, Zhang Y, Wang F, Hooper DC. Plasmid-mediated quinolone resistance in clinical isolates of Escherichia coli from Shanghai, China. Antimicrob Agents Chemother 2003;47:22428.

20. Jiang Y, Zhou Z, Qian Y, Wei Z, Yu Y, Hu S, et al. Plasmid-mediated quinolone resistance determinants qnr and $\operatorname{aac}\left(6^{\prime}\right)-I b-c r$ in extended-spectrum beta-lactamase-producing Escherichia coli and Klebsiella 
pneumoniae in China. J Antimicrob Chemother 2008;61:1003-6.

21. Wang M, Guo Q, Xu X, Wang X, Ye X, Wu S, et al. New plasmid-mediated quinolone resistance gene, $q n r C$, found in a clinical isolate of proteus mirabilis. Antimicrob Agents Chemother 2009;53:1892-7.

22. Cavaco LM, Hasman $\mathrm{H}$, Xia S, Aarestrup FM. qnrD, a novel gene conferring transferable quinolone resistance in Salmonella enterica serovar Kentucky and Bovismorbificans strains of human origin. Antimicrob Agents Chemother 2009;53:603-8.

23. Yamane K, Wachino J, Suzuki S, Kimura K, Shibata N, Kato H, et al. New plasmid-mediated fluoroquinolone efflux pump, QepA, found in an Escherichia coli clinical isolate. Antimicrob Agents Chemother 2007;51:3354-60.

24. Sandvang D, Aarestrup FM. Characterization of aminoglycoside resistance genes and class 1 integrons in porcine and bovine gentamicin-resistant Escherichia coli. Microb Drug Resist 2000;6:19-27.

25. Dallenne C, Da Costa A, Decré D, Favier C, Arlet G. Development of a set of multiplex PCR assays for the detection of genes encoding important beta-lactamases in Enterobacteriaceae. J Antimicrob Chemother 2010;65 490-5.

26. Van TT, Chin J, Chapman T, Tran LT, Coloe PJ. Safety of raw meat and shellfish in Vietnam: an analysis of Escherichia coli isolations for antibiotic resistance and virulence genes. Int J Food Microbiol 2008;124:217-23.

27. Sandvang D, Aarestrup FM, Jensen LB. Characterisation of integrons and antibiotic resistance genes in Danish multiresistant Salmonellaenterica Typhimurium DT104. FEMS Microbiol Lett 1998;160:37-41.

28. Maynard C, Fairbrother JM, Bekal S, Sanschagrin F, Levesque RC, Brousseau R, et al. Antimicrobial resistance genes in enterotoxigenic Escherichia coli 0149:K91 isolates obtained over a 23-year period from pigs. Antimicrob Agents Chemother 2003;47:3214-21.

29. Sengel $\varnothing v$ G, Agers $\varnothing$ Y, Halling-Sørensen B, Baloda SB, Andersen JS, Jensen LB. Bacterial antibiotic resistance levels in Danish farmland as a result of treatment with pig manure slurry. Environ Int 2003;28:587-95.

30. Ng LK, Mulvey MR, Martin I, Peters GA, Johnson W. Genetic characterization of antimicrobial resistance in Canadian isolates of Salmonella Serovar Typhimurium DT104. Antimicrob Agents Chemother 1999;43:3018-21.

31. Sáenz Y, Briñas L, Domínguez E, Ruiz J, Zarazaga M, Vila J, et al. Mechanisms of resistance in multiple-antibioticresistant Escherichia coli strains of human, animal, and food Origins. Antimicrob Agents Chemother 2004;48:3996-4001. 
32. Do KH, Byun JW, Lee WK. Prevalence of O-serogroups, virulence genes, and F18 antigenic variants in Escherichia coli isolated from weaned piglets with diarrhea in Korea during 2008-2016. J Vet Sci 2019;20:43-50.

33. Johnson TJ, Wannemuehler YM, Johnson SJ, Logue CM, White DG, Doetkott C, et al. Plasmid replicon typing of commensal and pathogenic Escherichia coli isolates. Appl Environ Microbiol 2007;73:1976-83.

34. Tamang MD, Nam HM, Jang GC, Kim SR, Chae MH, Jung SC, et al. Molecular characterization of extended-spectrum-b-lactamase-producing and plasmid-mediated AmpC b-lactamase-producing Escherichia coli isolated from stray dogs in South Korea. Antimicrob Agents Chemother 2012;56:270512.

35. Patel K, Goldman JL. Safety Concerns Surrounding Quinolone Use in Children. J Clin Pharmacol 2016;56:1060-75.

36. Threlfall EJ, Cheasty T, Graham A, Rowe B. High-level resistance to ciprofloxacin in Escherichia coli. Lancet 1997;349:403.

37. Li Y, Chen L, Wu X, Huo S.. Molecular characterization of multidrug-resistant avian pathogenic Escherichia coli isolated from septicemic broilers. Poult Sci 2015;94:601-11.

38. Mitra S, Mukherjee S, Naha S, Chattopadhyay P, Dutta S, Basu S. Evaluation of co-transfer of plasmidmediated fluoroquinolone resistance genes and blaNDM gene in Enterobacteriaceae causing neonatal septicaemia. Antimicrob Resist Infect Control 2019;8:46.

39. Seo KW, Lee YJ. Prevalence and Characterization of Plasmid-Mediated Quinolone Resistance Determinants qnrand aac(6')-Ib-cr in Ciprofloxacin-Resistant Escherichia coli Isolates from Commercial Layer in Korea. J Microbiol Biotechnol 2020;30:1180-3.

40. Gyles CL. Fimbriae of Escherichia coli. In: Gyles CL (ed.). Escherichia coli in Domestic Animals and Humans. pp. 399-436, CAB International, Wallingford. 1994.

41. Blanco M, Lazo L, Blanco JE, Dahbi G, Mora A, López C, et al. Serotypes, virulence genes, and PFGE patterns of enteropathogenic Escherichia coli isolated from Cuban pigs with diarrhea. Int Microbiol 2006;9:53-60.

42. Sato JPH, Takeuti KL, Andrade MR, Koerich PKV, Tagliari V, Bernardi ML, et al.. Virulence profiles of enterotoxigenic Escherichia coli isolated from piglets with post-weaning diarrhea and classification according to fecal consistency. Pesq Vet Bras 2016;36:253-7.

43. Noamani BN, Fairbrother JM, Gyles CL. Virulence genes of 0149 enterotoxigenic Escherichia coli from outbreaks of postweaning diarrhea in pigs. Vet Microbiol 2003;97:87-101. 
44. Chen X, Gao S, Jiao X, Liu XF. Prevalence of serogroups and virulence factors of Escherichia coli strains isolated from pigs with postweaning diarrhoea in eastern China. Vet Microbiol 2004;103:13-20.

45. Bolon MK. The newer fluoroquinolones. Med Clin N Am 2011;95:793-817.

46. Uchida Y, Mochimaru T, Morokuma Y, Kiyosuke M, Fujise M, Eto F, et al. Geographic distribution of fluoroquinolone-resistant Escherichia coli strains in Asia. Int J Antimicrob Agents 2010;35:387-91.

47. Yang J, Luo Y, Li J, Ma Y, Hu C, Jin S, et al. Characterization of clinical Escherichia coli isolates from China containing transferable quinolone resistance determinants. J Antimicrob Chemother 2010;65:4539.

48. Vila J, Ruiz J, Marco F, Barcelo A, Goñi P, Giralt E, et al. Association between double mutation in gyrA gene of ciprofloxacin-resistant clinical isolates of Escherichia coli and MICs. Antimicrob Agents Chemother 1994;38:2477-9.

49. Domínguez E, Zarazaga M, Sáenz Y, Briñas L, Torres C. Mechanisms of antibiotic resistance in Escherichia coli isolates obtained from healthy children in Spain. Microb Drug Resist 2002;8:321-7.

50. Röderova M, Halova D, Papousek I, Dolejska M, Masarikova M, Hanulik V, et al. Characteristics of Quinolone Resistance in Escherichia coli Isolates from Humans, Animals, and the Environment in the Czech Republic. Front Microbiol 2017;7:2147.

51. Yu T, Jiang X, Fu K, Liu B, Xu D, Ji S, et al. Detection of extended-Spectrum beta-lactamase and plasmid-mediated quinolone resistance determinants in Escherichia coli isolates from retail meat in China. J Food Sci. 2015;80:M1039-M1043.

52. Pereira RV, Foditsch C, Siler JD, Dulièpre SC, Altier C, Garzon A, et al. Genotypic antimicrobial resistance characterization of $E$. coli from dairy calves at high risk of respiratory disease administered enrofloxacin or tulathromycin. Sci Rep 2020;10:19327.

53. Ruiz J. Mechanisms of resistance to quinolones: target alterations, decreased accumulation and DNA gyrase protection. J Antimicrob Chemother 2003;51:1109-17.

54. Jacoby GA. Mechanisms of resistance to quinolones. Clin Infect Dis 2005;41:S120-S126.

55. Paterson DL, Bonomo RA. Extended-spectrum beta-lactamases: a clinical update. Clin Microbiol Rev 2005;18:657-86.

56. Seo KW, Lee YJ. Detection of plasmid-mediated quinolone resistance genes in b-lactamase-producing Escherichia coli isolates from layer hens. Poult Sci 2019;98:1480-7.

57. Xue G, Li J, Feng Y, Xu W, Li S, Yan C, et al. High prevalence of plasmid-mediated quinolone resistance determinants in Escherichia coli and Klebsiella pneumoniae isolates from pediatric patients in China. 
Microb Drug Resist 2017;23:107-14.

58. Kang HY, Jeong YS, Oh JY, Tae SH, Choi CH, Moon DC, et al. Characterization of antimicrobial resistance and class 1 integrons found in Escherichia coli isolates from humans and animals in Korea. J Antimicrob Chemother 2005;55:639-44.

59. Yang QE, Sun J, Li L, Deng H, Liu BT, Fang LX, et al. IncF plasmid diversity in multi-drug resistant Escherichia coli strains from animals in China. Front Microbiol 2015;6:964.

60. Fairbrother JM, Nadeau E, Gyles CL. Escherichia coli in postweaning diarrhea in pigs: an update on bacterial types, pathogenesis, and prevention strategies. Anim Health Res Rev 2005;6:17-39.

61. Nguyen UV, Coddens A, Melkebeek V, Devriendt B, Goetstouwers T, Poucke MV, et al. High susceptibility prevalence for F4+ and F18+ Escherichia coli in Flemish pigs. Vet Microbiol 2017;202:52-7.

62. Zhang W, Zhao M, Ruesch L, Omot A, Francis D. Prevalence of virulence genes in Escherichia coli strains recently isolated from young pigs with diarrhea in the US. Vet Microbiol 2007;123:145-52.

63. Kusumoto M, Hikoda Y, Fujii Y, Murata M, Miyoshi H, Ogura Y, et al. Emergence of a multidrugresistant Shiga toxin-producing enterotoxigenic Escherichia coli lineage in diseased swine in Japan. J Clin Microbiol 2016;54:1074-81.

64. Luppi A, Gibellini M, Gin T, Vangroenweghe F, Vandenbroucke V, Bauerfeind R, et al. Prevalence of virulence factors in enterotoxigenic Escherichia coli isolated from pigs with post-weaning diarrhoea in Europe. Porcine Health Manag 2016;2:20.

65. Byun JW, Jung BY, Kim HY, Fairbrother JM, Lee MH, Lee WK. O-serogroups, virulence genes of pathogenic Escherichia coli and pulsed-field gel electrophoresis (PFGE) patterns of 0149 isolates from diarrhoeic piglets in Korea. Vet Med (Praha) 2013;58:468-76.

66. Leclerc S, Boerlin P, Gyles C, Dubreuil JD, Mourez M, Fairbrother JM, et al. Paa, originally identified in attaching and effacing Escherichia coli, is also associated with enterotoxigenic E. coli. Res Microbiol 2007;158:97-104.

\section{Tables}

Due to technical limitations, table 1-4 is only available as a download in the Supplemental Files section.

\section{Supplementary Files}

This is a list of supplementary files associated with this preprint. Click to download.

- Tables.pdf 